\title{
Investigation of Topologies and Control Strategies of Fuel Cell Vehicles
}

\author{
Nan Xu' ${ }^{1}$, Yuanjian Zhang ${ }^{1}$, Zicheng $\mathrm{Fu}^{1}$, Di Zhao ${ }^{1}$, Liang Chu ${ }^{1,{ }^{*}}$, Feikun Zhou ${ }^{2}$ \\ ${ }^{1}$ State Key Laboratory of Automotive Simulation and Control, Jilin University, Changchun, 130025, \\ China
}

${ }^{2}$ China FAW Group Corporation R\&D Center, Changchun, 130011, China

Keywords: Fuel Cell Vehicle, Topologies, Control Strategies.

\begin{abstract}
This paper mainly provide the discussion of the topologies applied in the fuel cell vehicles and related control strategy. The fuel cell vehicles acquires power from the fuel cell stack or from multi power sources like fuel cell stack and battery, so there are quite a few topologies can be applied in the fuel cell vehicle. According to the different topologies, there are many control strategies can be made use of to make sure the fuel cell vehicle can operate in a smooth and high efficiency state.
\end{abstract}

\section{Introduction}

Currently, the starving of the fossil energy and the deterioration of the environment have been widely focused. Meanwhile, more and more green gas has caused the increasing of the temperature of the earth. To solve the problem, many researchers have been involved. In the auto industry, the novel energy vehicle has been treated as an ideal solution to solve the problems. Among the novel energy vehicles, the fuel cell vehicles are deeply researched for its zero emission, high efficiency, and reasonable performance. Due to the characteristic of the fuel cell stack itself, the fuel cell vehicle with single fuel cell stack cannot fully meet the requirement of vehicle driving. Hence, researchers propose the hybrid power topologies, such as the fuel cell stack together with battery, fuel cell stack together with ultra-capacitor, .etc. The existence of the other power sources except the fuel cell stack can offset the drawbacks of fuel cell stack, such as the poor quick response performance, poor cold start performance, and fuel's effect of hunger.

Just like renewable energy vehicles, there are amount of control strategies can be applied in the fuel cell vehicles. Chang-jun Xie applies the neural network theory in the control of fuel cell vehicles [1]. Xiangjun Li employs the fuzzy logic theory in the control of fuel cell vehicles [2]. Omar Hegazy make use of the particle swarm theory to perform energy management in fuel cell vehicle [3]. By applying the advanced control theory, the fuel cell vehicle can operate in a desired state. In the following parts, the topologies of fuel cell vehicles and the control strategy of fuel cell vehicles are elaborative discussed.

\section{Topologies of Fuel Cell Vehicle}

According to the types of the power sources in the fuel cell vehicle, the topologies of fuel cell vehicle can be divided into two types, the single power source topology, and the multi power sources topologies.

\section{Single power source topology}

The fuel cell vehicle that with single power topology is driven by the fuel cell stack only. The illustration of this topology can be seen in figure 1;

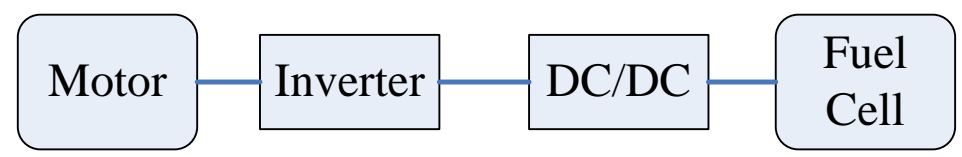

Fig.1: Single power source topology

In this topology, the fuel cell stack performs as single power source, making the structure quite simple. It also reduce the difficulty of the space layout and just requires simple energy management 
or control strategy. However, this topology has some drawbacks that make it less likely be used in fuel cell vehicles. This topology requires high power fuel cell stack, which means the cost of the fuel cell stack should be quite high. The output power of the fuel cell stack follows the requirement of the vehicle driving. When the vehicle operating in low load mode, the efficiency of the fuel cell stack could be quite low, which is not benefit for the energy-saving effect. Moreover, the fuel cell stack cannot instantly follow the requirement of vehicle driving, the acceleration of the vehicle cannot be perfect.

\section{The multi power sources topology}

Depends on the type and the amount of the other power source except the fuel cell stack, the multi power sources topology can be divided into following types

The full power topology. The full power topology is made up of the fuel cell stack and another type of power source that commonly is battery or ultra-capacitor. The illustration of this topology can be seen in figure 2 and figure 3.

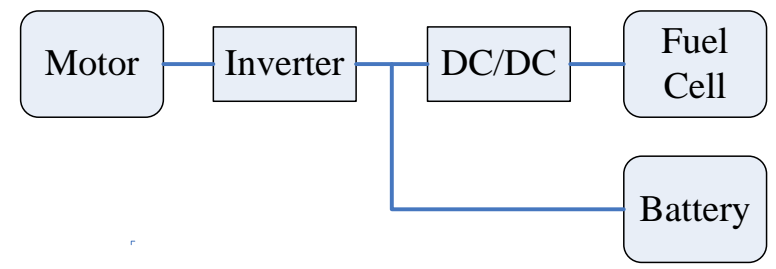

Fig.2: Full power topology with battery

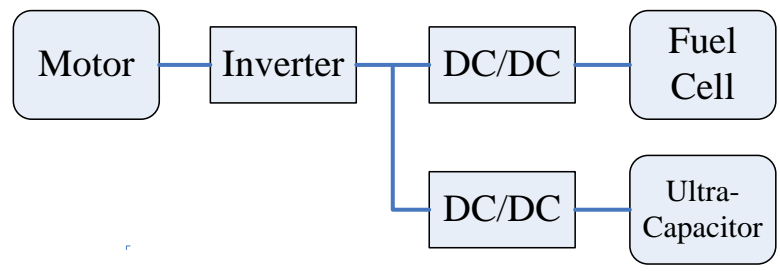

Fig.3: Full power topology with ultra-capacitor

In the full power topology, the fuel cell stack performs as the main power source to provide most power during the vehicle operating in the steady state. The battery or ultra-capacitor performs as the second power sources to provide the power during the vehicle accelerating or the vehicle decelerating, especially brake energy regeneration. The second power source can offset the drawback of the poor response performance of the fuel cell stack, prolong the lifetime of the fuel cell stack. In the full power topology, the battery or the ultra-capacitor can also be connected to the DC bus through the DC/DC converter, making the parameter matching of the battery or ultracapacitor more flexible. However, the existence of the second power source can increase the total weight of the fuel cell vehicle. This topology also requires a high performance of the fuel cell stack. The full power topology now is widely accepted in the fuel cell vehicle, such as in Toyota Mirai, Hyundai Tucson [4-5].

Three power sources topology. In this topology, there are three power sources, the fuel cell stack, the batter, and the ultra-capacitor. The fuel cell stack also performs as the main power source, the battery and the ultra-capacitor perform as the aided power source. The illustration of this topology can be seen in figure 4 . 


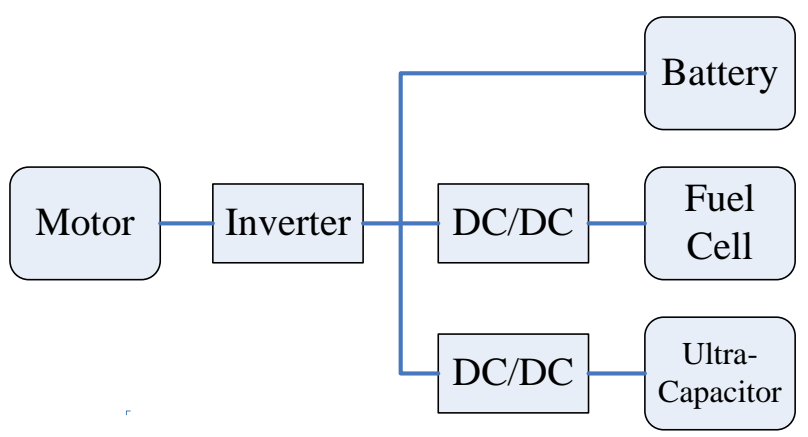

Fig.4: Three power sources topology

The ultra-capacitor is a power source which holds reasonable power density and long lifetime. These characteristic makes it can operate during vehicle accelerating and decelerating, decrease the harm to battery and offset the disadvantage of the slow response of fuel cell stack. The battery in this topology mainly provides the power when the vehicle operating in the high power mode and recycle the braking power when the ultra-capacitor charged to full state. This topology can make full use of the advantage of different power sources but makes the energy management of the fuel cell vehicle much more complex.

Series topology. In the series topology, there are two power sources, the fuel cell stack and the battery. The illustration of this topology can be seen in figure 5 .

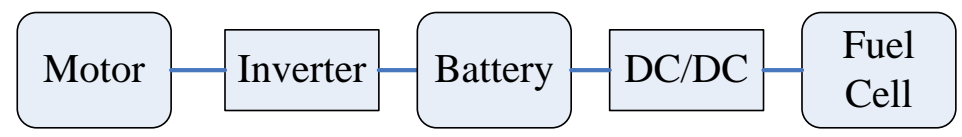

Fig.5: Series topology

In the series topology, the battery performs the main power source to drive the vehicle. When the SOC (State of Charge) value lower than the set minimum value, the fuel cell stack starts work to charge the battery and drive the vehicle. This topology lowers the requirement to the fuel cell stack, which means the power of fuel cell stack can be small, decreasing the cost of total topology. This type of topology is quite similar to the range extended electric vehicle or plug-in hybrid electric vehicle. However, this topology needs a large capacity battery and requires frequently charge and discharge. This topology also widely used for its low cost characteristic, the SAIC fuel cell vehicle just uses this topology.

From the upper discussion, the full power topology and the series topology now are widely used. The full power topology can realize ideal driving mileage and make full use of the advantages of fuel cell stack. The series topology also is a rational solution.

\section{Control strategy of fuel cell vehicle}

In this part, the control strategies of the fuel cell vehicles with full power topology and the series Control strategy of fuel cell vehicles with full power topology

To the control strategy of fuel cell vehicles with full power topology, a lot of control theory can be used. Here, a certain rule based control strategy is discussed. This type of control strategy mainly depends on following parameters, the required driving power $\mathrm{P}_{\text {req, }}$ the SOC (State of Charge) of battery, the maximum power of fuel cell stack $\mathrm{P}_{\max }$. The details of this control strategy can be seen as follows.

When $\mathrm{P}_{\text {req }}$ is larger than the $\mathrm{P}_{\max }$, the SOC of battery is larger than $\mathrm{SOC}_{\min }$, the fuel cell stack together with battery drives the vehicle. 
When $\mathrm{P}_{\text {req }}$ is larger than the $\mathrm{P}_{\max }$, the SOC of battery is lower than $\mathrm{SOC}_{\min }$, the vehicle operates in a low velocity mode and the fuel cell stack drives the vehicle and charges the battery at the same time.

When Preq is smaller than the $\mathrm{P}_{\max }$, the SOC of battery is larger than $\mathrm{SOC}_{\min }$, the fuel cell stack drives the vehicle alone.

When Preq is smaller than the $\mathrm{P}_{\max }$, the SOC of battery is lower than $\mathrm{SOC}_{\min }$, the fuel cell stack drives the vehicle and charges the battery.

\section{Control strategy of fuel cell vehicles with series topology}

The control strategy of fuel cell vehicles with series topology is quite similar with the control strategy applied in the range extended electric vehicle. Here, the rule based control strategy is discussed. This type of control strategy mainly depends on the SOC (State of Charge) value of battery. The details of this control strategy can be seen as follows.

When the SOC of battery is larger than the $\mathrm{SOC}_{\min }$, the battery provide energy to drive the vehicle.

When the SOC of battery is lower than the $\mathrm{SOC}_{\min }$, the vehicle operates in a low velocity mode, the fuel cell stack drives the vehicle and charges the battery.

\section{Conclusion}

In this paper, different topologies applied in the fuel cell vehicle is discussed. Based on the full power source topology and the series topology, two control strategy is proposed which are suitable and easy to deploy. In the next step, the advanced control strategy would further investigated, to increase the efficiency of the fuel cell vehicles.

\section{Reference}

[1] Chang-jun Xie, Shu-hai Quan, Qi-hong Chen, Control Strategy of Hybrid Power System for Fuel Cell Electric Vehicle based on Neural Network Optimization, Proceedings of the IEEE International Conference on Automation and Logistics, ICAL ,p.753-757,2008

[2] Xiangjun Li, Jianqiu Li, Liangfei Xu, Minggao Ouyang, Power management and economic estimation of fuel cell hybrid vehicle using fuzzy logic, 5th IEEE Vehicle Power and Propulsion Conference, VPPC'09,p.1749-1754,2009

[3] Omar Hegazy, Joeri Van Mierlo, Particle Swarm Optimization for Optimal Powertrain Component Sizing and Design of Fuel Cell Hybrid Electric Vehicle, Proceedings of the International Conference on Optimisation of Electrical and Electronic Equipment,OPTIM,p.601609,2010

[4] K. Ettihir, L. Boulon, K. Agbossou, and S. Kelouwani, MPPT Control Strategy on PEM Fuel Cell Low Speed Vehicle, 2012 IEEE Vehicle Power and Propulsion Conference, VPPC 2012,p. 926931,2012

[5] Jared Farnsworth, Tetsuya Bono, Hideaki Mizuno, Yutaka Tano, Masashi Toida, Development of a Vehicle Model for FCHV Control and Functional Specification Development within a Softwarein-the-Loop Simulation Environment, SAE Technical Papers, 2010-01-0939. 